\title{
Molecular-metabolic interaction of pituitary-adrenal axis with adrenocorticotropic and glucocorticoid hormone in Cushing's disease
}

Jie Ding

Peking Union Medical College Hospital

Ming Feng

Peking Union Medical College Hospital

Marcus Hacker

Medical University of Vienna

Li Huo ( $\nabla$ huoli@pumch.cn)

Peking Union Medical College Hospital https://orcid.org/0000-0003-1216-083X

\section{Xiang Li}

Medical university of Vienna

\section{Short Report}

Keywords: 68Ga-pentixafor, 18F-FDG, Cushing's disease, Pituitary-adrenal axis

Posted Date: September 8th, 2021

DOl: https://doi.org/10.21203/rs.3.rs-869037/v1

License: (c) (1) This work is licensed under a Creative Commons Attribution 4.0 International License. Read Full License 


\section{Abstract \\ Purpose}

This study aimed to investigate C-X-C motif chemokine receptor 4 (CXCR4) molecular signaling pathway and the glucose metabolism of pituitary-adrenal axis in Cushing's disease (CD) by using ${ }^{68}$ Ga-pentixafor and ${ }^{18} \mathrm{~F}$-FDG PET/CT.

\section{Methods}

We recruited eleven patients including 4 primary $C D, 3$ recurrent $C D$ and 4 non-functional pituitary adenoma (NFPA) patients. Both ${ }^{68} \mathrm{Ga}$-pentixafor PET/CT and ${ }^{18} \mathrm{~F}$-FDG PET/CT were performed. The radio-uptake of pituitary-adrenal axis was correlated with the hormone levels (including serum adrenocorticotropin, serum cortisol and 24-h urine free cortisol).

\section{Results}

The uptake of pituitary adenomas and bilateral adrenals in primary and recurrent CD patients were significantly higher than NFPA patients in ${ }^{68} \mathrm{Ga}$-pentixafor PET. Besides, hormone level was significantly correlated with the uptake of ${ }^{68} \mathrm{Ga}$-pentixafor in pituitary adenomas and adrenal tissue but not with glucose metabolism determined by ${ }^{18} \mathrm{~F}$-FDG PET.

\section{Conclusions}

In this pilot study, we found activated CXCR4 molecular signaling rather than glucose metabolism regulation along the pituitary-adrenal axis in CD patients. ${ }^{68} \mathrm{Ga}$-pentixafor PET/CT might have the potential in detecting ACTH-producing pituitary microadenoma.

\section{Introduction}

Cushing's disease (CD) is caused by an adrenocorticotropin-producing pituitary adenoma (ACTH-PA) that disrupts the pituitary-adrenal axis and stimulates cortisol production by the adrenal glands [1]. The underlying functional mechanisms, including metabolic derangements and specific molecular signaling, are crucial for disease development (Fig. 1). G protein-coupled receptors (GPCRs) mediate cell signal transduction and are modulated by various endogenous ligands [2, 3]. GPCRs are major signaling proteins that moderate numerous physiologic processes of relevance to endocrinology. C-X-C motif chemokine receptor 4 (CXCR4) is a typical GPCRs. Their expression and signaling may directly favor hormone hypersecretion and cells proliferation of pituitary adenoma [4, 5]. Molecular imaging of CXCR4 using the specific radioligand ${ }^{68} \mathrm{Ga}$-pentixafor, which had been proven to have promising potential in 
endocrine diseases [6-9]. Endocrinal ${ }^{68}$ Ga-pentixafor imaging quantifying molecular targets and their downstream signaling pathways was identified for diagnostic and therapeutic purposes in endocrine disease [6-9].

This study aimed to investigate the in vivo pituitary-adrenal CXCR4 signaling in CD patients by ${ }^{68} \mathrm{Ga}$ pentixafor PET/CT in correlation with hormone levels. In addition, we investigated the corresponding glucose metabolism of the pituitary-adrenal axis using ${ }^{18}$ F-FDG PET/CT.

\section{Materials And Methods}

\section{Patients}

Seven CD patients with primary $(n=4)$ and recurrent $(n=3)$ ACTH-PA and four patients with nonfunctional pituitary adenoma (NFPA) were included in our study. All patients underwent dynamic contrastenhanced MRI before PET/CT examination. In addition, the level of 24-h urine free cortisol (UFC), serum cortisol and serum ACTH were recorded.

Both ${ }^{18} \mathrm{~F}$-FDG PET/CT and ${ }^{68} \mathrm{Ga-pentixafor} \mathrm{PET/CT}$ were performed within 3 days in all patients. Within 1 week after image acquisition, 11 patients underwent transsphenoidal adenomectomy. The final confirmation was based on clinical variables, laboratory assessments, histopathology and follow-up evaluations. Informed consent was obtained from all patients prior to study participation and the consent form and study were approved by the Ethical Committee of PUMCH (IRB protocol \#ZS-1435).

\section{Image acquisition}

The preparation of ${ }^{68} \mathrm{Ga}$-pentixafor was conducted as has previously been described. All images were acquired using a dedicated PET/CT scanner (PoleStar m660; SinoUnion Healthcare Inc., Beijing, China) at the Peking Union Medical College Hospital after 40-60 min of an intravenous injection of ${ }^{68} \mathrm{Ga}$-pentixafor (111-185MBq, 3-5mCi) and ${ }^{18} \mathrm{~F}-\mathrm{FDG}$ (5.55 MBq per kilogram body weight). The acquisition area including whole body from the upper thigh to the thin ( $5-6$ bed position, $2 \mathrm{~min} / \mathrm{bed}$ ) and a single bed above the brain (5min). The patients fasted over 6 hours before injection of ${ }^{18} \mathrm{~F}-\mathrm{FDG}$.

\section{Image and Data Analysis}

In qualitative analysis, the ${ }^{18} \mathrm{~F}-\mathrm{FDG} \mathrm{PET} / \mathrm{CT}$ and ${ }^{68} \mathrm{Ga}$-pentixafor PET/CT images were independently analyzed by two experienced nuclear medicine physicians, and they finally reached a consensus in case of disagreement. Lesions in which tracer uptake was higher than the adjacent tissues with physiological uptake were considered PET positive. In semi-quantitative analysis, maximum standardized uptake value $\left(S_{\mathrm{V}} \mathrm{V}_{\max }\right)$ and total lesion glycolysis (TLG) of pituitary lesions and bilateral adrenal glands were measured. The location of PET negative pituitary lesions was estimated by the CT imaging or the surgical/histopathological findings.

\section{Statistical analysis}


The analysis was performed using the SPSS 22.0 software (IBM SPSS, Chicago, IL, USA) and the Prism 8.0 software (GraphPad, San Diego, CA). Quantitative variables were expressed as the mean \pm standard deviation. Student's $t$ test or Mann-Whitney U-test was used to compare the mean values between the two or three groups. The correlations between quantitative parameters were evaluated using the Pearson correlation coefficient or Spearman correlation coefficient. All tests were two-tailed, and $P<0.05$ was considered statistically significant.

\section{Results}

\section{Patients demographics and clinical characteristics}

Eleven patients (10 women and 1 man) aged $40 \pm 13$ years old were included in our study, which including $7 \mathrm{CD}$ patients and 4 patients with NFPA. The final diagnoses of pituitary adenomas included primary ACTH-PA $(n=4)$, recurrent ACTH-PA $(n=3)$ and NFPA $(n=4)$. All ACTH-PAs were microadenoma while all NFPA were macroadenoma. The results of pituitary MRI were positive for primary ACTH-PAs and NFPAs, but not for recurrent ACTH-PA. Details of patient demographics and clinical characteristics were listed in Table 1 and Supplemental table 1. 
Table 1

Clinical characteristics and imaging performance of the patients

\begin{tabular}{|c|c|c|c|c|}
\hline & $\begin{array}{l}\text { Primary ACTH- } \\
\text { producing pituitary } \\
\text { adenoma }(n=4)\end{array}$ & $\begin{array}{l}\text { Recurrent ACTH- } \\
\text { producing pituitary } \\
\text { adenoma }(n=3)\end{array}$ & $\begin{array}{l}\text { Non-functional } \\
\text { pituitary adenoma } \\
(n=4)\end{array}$ & $\begin{array}{l}P \\
\text { value }\end{array}$ \\
\hline Age & $40.8 \pm 9.7$ & $34.3 \pm 9.9$ & $44.8 \pm 18.6$ & 0.63 \\
\hline $\begin{array}{l}\text { Sex ratio } \\
\text { (female: } \\
\text { male) }\end{array}$ & $3: 1$ & $3: 0$ & $4: 0$ & 0.90 \\
\hline $\begin{array}{l}\text { Serum } \\
\text { cortisol } \\
(\mu \mathrm{g} / \mathrm{dl})\end{array}$ & $35.0 \pm 2.7$ & $32.6 \pm 8.5$ & $9.5 \pm 3.1$ & $\begin{array}{l}<.05 \\
0.05\end{array}$ \\
\hline $\begin{array}{l}\text { Serum ACTH } \\
(\mathrm{pg} / \mathrm{ml})\end{array}$ & $78.8 \pm 35.0$ & $148.5 \pm 144.2$ & $23.8 \pm 13.3$ & $\begin{array}{l}<.05 \\
0.05\end{array}$ \\
\hline $\begin{array}{l}\text { 24-h UFC } \\
(\mu \mathrm{g} / 24 \mathrm{hr})\end{array}$ & $643.3 \pm 357.2$ & $601.4 \pm 403.5$ & 33.8 & 0.31 \\
\hline $\begin{array}{l}\text { Detection rate } \\
\text { of pituitary } \\
\text { MRI }\end{array}$ & $100 \%(4 / 4)$ & $0 \%(0 / 3)$ & $100 \%(4 / 4)$ & $\begin{array}{l}<.05 \\
0.05\end{array}$ \\
\hline \multicolumn{5}{|c|}{${ }^{68} \mathrm{Ga}$-pentixafor in pituitary adenomas } \\
\hline $\begin{array}{l}\text { Visual } \\
\text { positive rate }\end{array}$ & $100 \%(4 / 4)$ & $67.7 \%(2 / 3)$ & $0(0 / 4)$ & $\hat{0}_{0.05}$ \\
\hline$S U V_{\max }$ & $5.9 \pm 0.5$ & $3.7 \pm 0.7$ & $2.2 \pm 0.6$ & $\dot{0} 01$ \\
\hline TLG & $4.4 \pm 1.2$ & $1.0 \pm 0.8$ & $1.5 \pm 0.6$ & $\begin{array}{l}<.05 \\
0.05\end{array}$ \\
\hline \multicolumn{5}{|c|}{${ }^{68} \mathrm{Ga}$-pentixafor in adrenal glands } \\
\hline$S U V_{\max }$ & $7.9 \pm 2.2$ & $9.3 \pm 0.7$ & $4.1 \pm 0.7$ & $\begin{array}{l}<.05 \\
0.05\end{array}$ \\
\hline TLG & $122.7 \pm 93.5$ & $79.4 \pm 30.2$ & $22.0 \pm 9.0$ & $\begin{array}{l}<.05 \\
0.05\end{array}$ \\
\hline \multicolumn{5}{|c|}{${ }^{18} \mathrm{~F}-\mathrm{FDG}$ in pituitary adenomas } \\
\hline $\begin{array}{l}\text { Visual } \\
\text { positive rate }\end{array}$ & $24 \%(1 / 4)$ & $0 \%(0 / 3)$ & $50 \%(2 / 4)$ & 0.71 \\
\hline SUV $_{\max }$ & $5.1 \pm 1.8$ & $3.7 \pm 1.1$ & $12.3 \pm 15.7$ & 0.46 \\
\hline
\end{tabular}

$P<0.05$ : statistical significance of the difference between the three groups.

Abbreviations: ACTH: adrenocorticotropin; UFC: urine free cortisol; TLG: total lesion glycolysis. 


\begin{tabular}{|c|c|c|c|c|}
\hline & $\begin{array}{l}\text { Primary ACTH- } \\
\text { producing pituitary } \\
\text { adenoma }(n=4)\end{array}$ & $\begin{array}{l}\text { Recurrent ACTH- } \\
\text { producing pituitary } \\
\text { adenoma }(n=3)\end{array}$ & $\begin{array}{l}\text { Non-functional } \\
\text { pituitary adenoma } \\
(n=4)\end{array}$ & $\begin{array}{l}P \\
\text { value }\end{array}$ \\
\hline TLG & $3.4 \pm 1.5$ & $1.1 \pm 0.4$ & $70.6 \pm 122.5$ & 0.06 \\
\hline \multicolumn{5}{|c|}{${ }^{18} \mathrm{~F}-\mathrm{FDG}$ in adrenal glands } \\
\hline SUV $_{\max }$ & $3.6 \pm 2.2$ & $3.0 \pm 0.9$ & $3.0 \pm 1.1$ & 0.91 \\
\hline TLG & $56.3 \pm 68.4$ & $21.1 \pm 15.4$ & $21.0 \pm 5.6$ & 0.52 \\
\hline $\begin{array}{l}\text { Pituitary } \\
\text { adenomas } \\
\text { sizes (mm) }\end{array}$ & $7.0 \pm 1.8$ & $4.0 \pm 1.0$ & $25.8 \pm 10.3$ & $\begin{array}{l}< \\
0.01\end{array}$ \\
\hline \multicolumn{5}{|c|}{$P<0.05$ : statistical significance of the difference between the three groups. } \\
\hline Abbreviati & H: adrenocorticotr & C: urine free cortiso & tal lesion glycolysi & \\
\hline
\end{tabular}

\section{The uptake of ${ }^{68} \mathrm{Ga}$-pentixafor $/{ }^{18} \mathrm{~F}$-FDG in pituitary adenomas and adrenal glands}

All primary ACTH-producing pituitary adenomas, 66.7\% (2/3) recurrent ACTH-PAs and no NFPAs showed positive in ${ }^{68} \mathrm{Ga}$-pentixafor PET (Fig. 2). Notably, the 2 positive recurrent ACTH-PAs were negative in pituitary MRI. However, only 1 primary ACTH-PA and 2 NFPAs were positive in ${ }^{18} \mathrm{~F}$-FDG PET.

The ${ }^{68} \mathrm{Ga}$-pentixafor $\mathrm{SUV}_{\max }$ of ACTH-PAs was significantly higher than that of NFPAs (Table 1 and Fig. 2). Meanwhile, the ${ }^{68} \mathrm{Ga}$-pentixafor TLG of primary ACTH-PAs $(4.4 \pm 1.2, n=4)$ was significantly higher than that of NFPAs $(1.5 \pm 0.6, n=4, P<0.01)$. Besides, the $S U V_{\max }$ and TLG of ${ }^{68} \mathrm{Ga}$-pentixafor in adrenal glands of $C D$ patients were significantly higher than that in patients with NFPA (SUV $\max : 8.5 \pm 1.8$ vs. $4.1 \pm 0.7, P<0.01$, TLG: $104.1 \pm 72.2$ vs. $22.0 \pm 9.0, P<0.05, \mathrm{n}=7$ vs.4, Fig. 3 ).

However, the SUV $\max$ and TLG of ${ }^{18} \mathrm{~F}$-FDG between ACTH-PAs and NFPAs had no significant difference (Table 1). Same as the SUV $\max$ and TLG of ${ }^{18} \mathrm{~F}-F D G$ in adrenal glands between CD patients and patients with NFPA (Table 1).

\section{Correlations of pituitary-adrenal axis hormone level with the uptake of ${ }^{68} \mathrm{Ga}$-pentixafor/ ${ }^{18} \mathrm{~F}$-FDG in pituitary adenomas}

The level of serum ACTH and serum cortisol were significantly correlated with ${ }^{68}$ Ga-pentixafor SUV max $_{\text {in }}$ pituitary adenomas ( $r=0.71$ and $r=0.80$, respectively, both $P<0.05$, Fig. 4), but the association between hormone level and TLG of ${ }^{68} \mathrm{Ga}$-pentixafor was not statistically significant in pituitary adenomas (Fig. 4). Notably, there was no statistically significant correlation between hormone level and SUV max $_{\text {or }}$ TLG of ${ }^{18}$ F-FDG in pituitary adenomas (Supplemental table 2). 
Correlations of pituitary-adrenal axis hormone level with the uptake of ${ }^{68} \mathrm{Ga}$-pentixafor/ ${ }^{18} \mathrm{~F}$-FDG uptake in adrenal glands

The hormone level was significantly correlated with $S U V_{\max }$ and TLG of ${ }^{68} \mathrm{Ga}$-pentixafor of adrenal glands in all patients (Fig. 4). However, there was no significant correlation between hormone level and ${ }^{18}$ F-FDG SUV $_{\text {max }}$ and TLG in adrenal glands (Supplemental table 2). In addition, the hormone level was significantly correlated with the uptake of ${ }^{68} \mathrm{Ga}$-pentixafor in pituitary adenomas and adrenal glands, but not for ${ }^{18}$ F-FDG (Fig. 4).

\section{Correlations of the ${ }^{68} \mathrm{Ga}$-pentixafor/ ${ }^{18} \mathrm{~F}-\mathrm{FDG}$ uptake in pituitary adenomas and adrenal glands}

The ${ }^{68} \mathrm{Ga-pentixafor} S \mathrm{SU}_{\max }$ of pituitary adenomas was significantly correlated with that of adrenal glands $(r=0.66, P<0.05, \mathrm{n}=11)$, but not for TLG $(r=0.30, P=0.36, \mathrm{n}=11)$. However, no significant correlations were found between ${ }^{18} \mathrm{~F}-\mathrm{FDG}$ SUV $\mathrm{max}_{\max }$ or TLG of pituitary adenomas and that of adrenal glands (Supplemental table 2).

\section{Discussion}

Different mediators signal along the pituitary-adrenal axis to connect hormonal and metabolic systems for the coordination of physiological processes. The systemic interactions were challenging to assess mechanistically furtherly. In this study, we first performed an observational study using PET revealed novel insights into hormonal crosstalk in CD. We found concomitant biochemical activation of the pituitary-adrenal axis in ACTH-producing pituitary microadenoma by ${ }^{68} \mathrm{Ga}$-pentixafor PET/CT, which potentially determine functional pituitary adenomas. The uptake of ${ }^{68} \mathrm{Ga}$-pentixafor in pituitary adenoma and adrenal glands were correlated with ACTH and cortisol levels, respectively. However, there was no association between the hormone production and symmetric endogenous glucose metabolism correspondingly.

The ectopic or aberrant expression of GPCRs is crucial in regulating cortisol. It has previously been reported that overexpression of CXCR4 in pituitary adenomas, whose ligand induces autocrine/paracrine proliferation in pituitary tumor cells, and it likely contributes to adenoma development, proliferation and hormone hypersecretion [4]. GPCRs could induce the synthesis and secretion of adrenocortical hormones eg. cortisol and aldosterone [5], which could be detected by ${ }^{68}$ Ga-pentixafor PET/CT [6-9]. This interactive molecular signaling pituitary-adrenal glands and correlation with hormone level was determined in this study. Hence, ${ }^{68} \mathrm{Ga}$-pentixafor PET/CT proved to be an extremely powerful analytical methodology that enabled to analyze symmetric molecular and cellular processes in $C D$ disease.

Activation and modulation of hormonal response could also be triggered through glucose metabolic signals. The theoretical underpinnings of ${ }^{18}$ F-FDG-PET use were established in early studies that showed 
slight net oxidation of glucose by either the Krebs'cycle or the pentose phosphate pathway in the normal pituitary gland $[10,11] .{ }^{18} \mathrm{~F}-\mathrm{FDG}$ PET results hinted at metabolic reprogramming of pituitary adenomas to rely on glycolysis as the primary energy source, similar to the Warburg effect in malignant tumors [12]. However, we did not find an association between pituitary-adrenal ${ }^{18} \mathrm{~F}$-FDG uptake and the serum ACTH/cortisol level. Besides, ${ }^{18} \mathrm{~F}$-FDG showed a limited role in detecting ACTH-producing pituitary microadenomas.

CXCR4 antagonists are potential novel molecules and possible future targets for CD treatment. Further pharmacological perturbations of CXCR4 antagonists on pituitary-adrenal axis might potentially allow a theragnostic approach to inhibit the production of endogenous ligands [13]. In future investigations, a closely entangled framework of in vivo biochemical process and hormonal response in endocrine diseases is required to enable a holistic analysis of pathomechanisms.

The major limitation of our study was the small number of included patients. Besides, the lower spatial resolution and partial volume effect of PET/CT could affect the accuracy of the results, especially in recurrent ACTH-PAs. Therefore, evidence-based outcome evaluation of this symmetric probing or metabolic signaling on a cross-organ level is warranted, especially compared to ${ }^{18} \mathrm{~F}$-FDG.

\section{Conclusion}

In this pilot study, we found in vivo activated CXCR4 molecular signaling along the pituitary-adrenal axis in $\mathrm{CD}$ patients in correlation with overexpression of ACTH and glucocorticoid. There was no corresponding glucose metabolism activation detected. Thus, ${ }^{68} \mathrm{Ga}$-pentixafor PET/CT might characterize $\mathrm{CD}$ and be a valuable tool for diagnosing ACTH-producing pituitary microadenoma.

\section{Declarations}

\section{DISCLOSURE}

This work was sponsored in part by the National Key Research and Development Program of China (Grant No. 2016YFC0901500), Center for Rare Diseases Research, Chinese Academy of Medical Sciences, Beijing, China (Grant No. 2016ZX310174-4), CAMS Innovation Fund for Medical Sciences(CIFMS; No. 2016-I2M-1-002), National Natural Science Foundation of China (Grant No. 82071967), Tsinghua University-Peking Union Medical College Hospital Initiative Scientific Research Program (Grant No. 20191080605), Capital 's Funds for Health Improvement and Research (CFH-2018-2-4014). No other potential conflict of interest relevant to this article was reported.

\section{COMPLIANCE WITH ETHICAL STANDARDS}

\section{Conflict of interest}

SCINTOMICS owns the IP on Pentixafor 


\section{Ethical approval}

The clinical institutional review board approved this study.

\section{Author contributions}

All authors contributed to the study conception and design. Material preparation, data collection and analysis were performed by Jie Ding, Ming Feng, Xiang Li and Li Huo. The first draft of the manuscript was written by Jie Ding and all authors commented on previous versions of the manuscript. All authors read and approved the final manuscript.

\section{ACKNOWLEDGMENT}

Thanks to Dr. Caixia Tian (Evomics Medical Technology Co., Ltd. Shanghai, China) for providing network analysis of multi-variables.

\section{References}

1. Melmed S. Pituitary-Tumor, Endocrinopathies. New Engl J Med. 2020;382(10):937-50. https://doi.org/10.1056/NEJMra1810772.

2. Lania AG, Mantovani G, Spada A. Mechanisms of disease: Mutations of G proteins and G-proteincoupled receptors in endocrine diseases. Nat Clin Pract Endocrinol Metab. 2006;2(12):681-93. https://doi.org/10.1038/ncpendmet0324.

3. Lania A, Mantovani G, Spada A. G protein mutations in endocrine diseases. Eur J Endocrinol. 2001;145(5):543-59. https://doi.org/10.1530/eje.0.1450543.

4. Barbieri F, Thellung S, Würth R, Gatto F, Corsaro A, Villa V, et al. Emerging Targets in Pituitary Adenomas: Role of the CXCL12/CXCR4-R7 System. Int J Endocrinol. 2014;2014:753524. https://doi.org/10.1155/2014/753524.

5. Lacroix A, Bourdeau I, Lampron A, Mazzuco TL, Tremblay J, Hamet P. Aberrant G-protein coupled receptor expression in relation to adrenocortical overfunction. Clin Endocrinol (Oxf). 2010;73(1):115. https://doi.org/10.1111/j.1365-2265.2009.03689.x.

6. Ding J, Zhang $Y$, Wen J, Zhang H, Wang H, Luo Y, et al. Imaging CXCR4 expression in patients with suspected primary hyperaldosteronism. Eur J Nucl Med Mol Imag. 2020;47(11):2656-65. https://doi.org/10.1007/s00259-020-04722-0.

7. Ding J, Tong A, Zhang Y, Wen J, Zhang H, Hacker M,et al. Functional characterization of adrenocortical masses in nononcological patients using [(68)Ga]-pentixafor. J Nucl Med. 2021. https://doi.org/10.2967/jnumed.121.261964. Online ahead of print.

8. Ding J, Tong A, Zhang Y, Zhang H, Huo L. Cortisol-Producing Adrenal Adenomas With Intense Activity on 68Ga-Pentixafor PET/CT. Clin Nucl Med. 2021;46(4):350-52.

https://doi.org/10.1097/RLU.0000000000003503. 
9. Ding J, Tong A, Zhang Y, Wen J, Huo L. Intense 68Ga-Pentixafor Activity in Aldosterone-Producing Adrenal Adenomas. Clin Nucl Med. 2020;45(4):336-9. https://doi.org/10.1097/RLU.0000000000002946.

10. Viña JR, Page RB, Davis DW, Hawkins RA. Aerobic glycolysis by the pituitary gland in vivo. J Neurochem. 1984;42(5):1479-82. https://doi.org/10.1111/j.1471-4159.1984.tb02814.x.

11. Boyle J, Patronas NJ, Smirniotopoulos J, Herscovitch P, Dieckman W, Millo C, et al. CRH stimulation improves (18)F-FDG-PET detection of pituitary adenomas in Cushing's disease. Endocrine. 2019;65(1):155-65. https://doi.org/10.1007/s12020-019-01944-7.

12. Vander Heiden MG, Cantley LC, Thompson CB. Understanding the Warburg effect: the metabolic requirements of cell proliferation. Science. 2009;324(5930):1029-33. https://doi.org/10.1126/science.1160809.

13. Cuevas-Ramos D, Fleseriu M. Treatment of Cushing's disease: a mechanistic update. J Endocrinol. 2014;223(2):R19-39. https://doi.org/10.1530/JOE-14-0300.

\section{Figures}




\section{Cushing's disease}

\section{Glucose metabolism?}
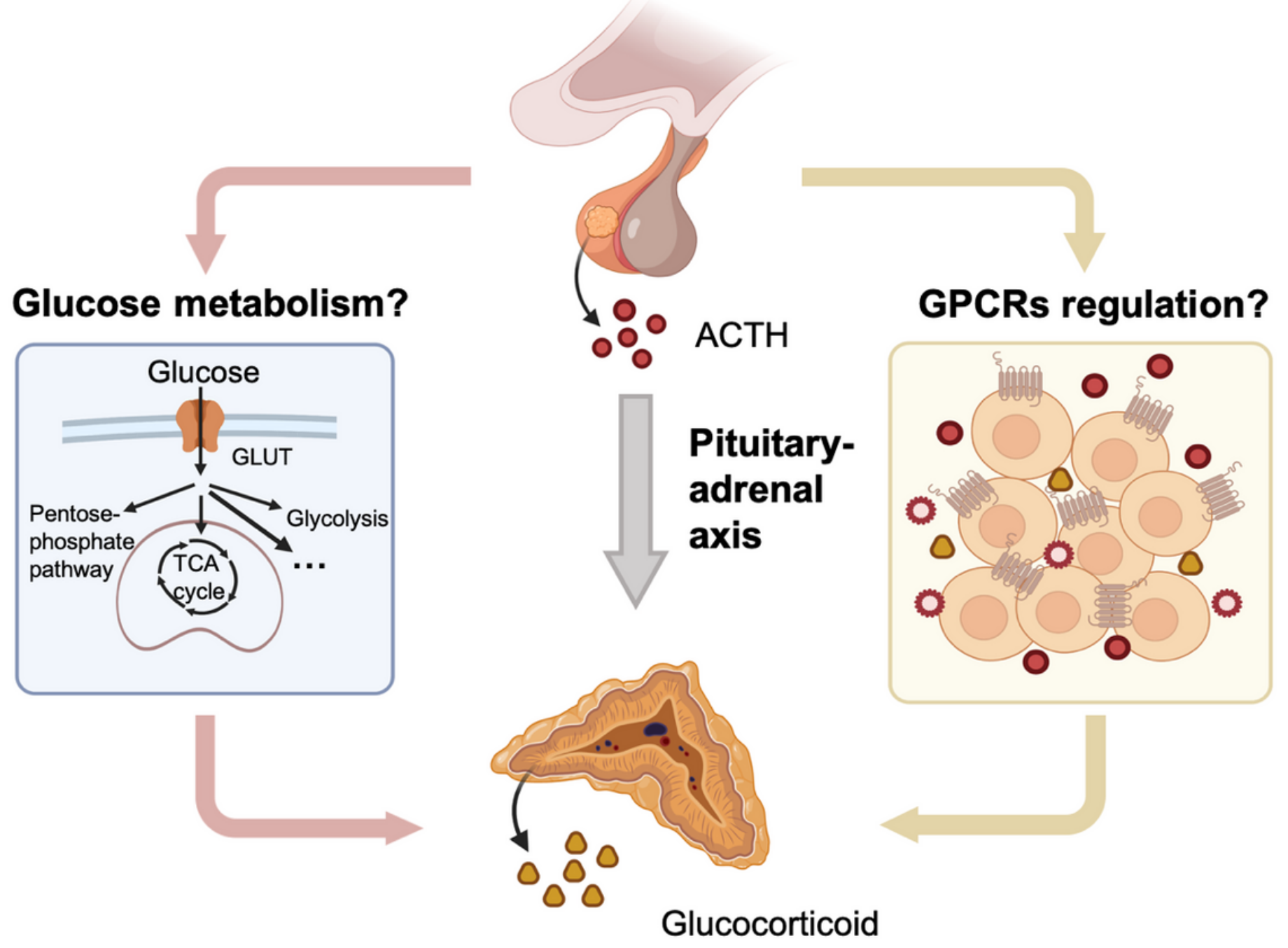

Figure 1

The purpose of this study. What is the possible mechanism of pituitary-adrenal axis in Cushing's disease, molecular regulation or glucose metabolism? 


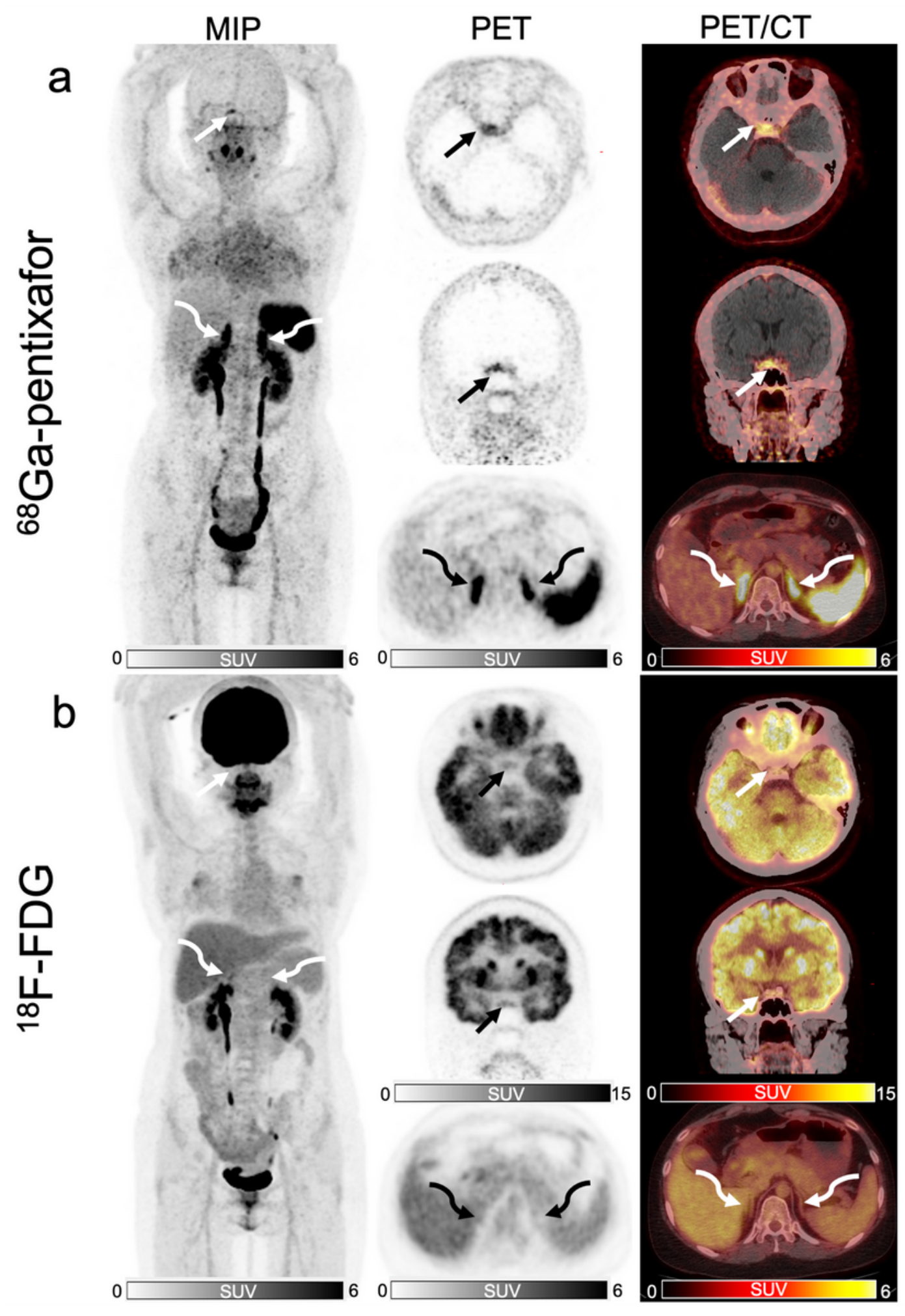

Figure 2

A 27-year-old female CD patient with facial plethora and increased waist circumference for two months. The images of maximum intensity projection (MIP), PET and axial fusion from the 68Ga-pentixafor (a) showed foci uptake in the right pituitary wing (SUVmax $=6.4$ and $T L G=3.8$, straight arrows) and obvious diffuse uptake in bilateral adrenal glands (SUVmax $=7.4$ and $T L G=117.9$, curved arrows) with normal morphology. However, the image of MIP, PET and axial fusion of 18F-FDG (b) showed slight uptake 
without obvious foci in the pituitary tissue (straight arrows) and no increased uptake in the adrenal glands (curved arrows).

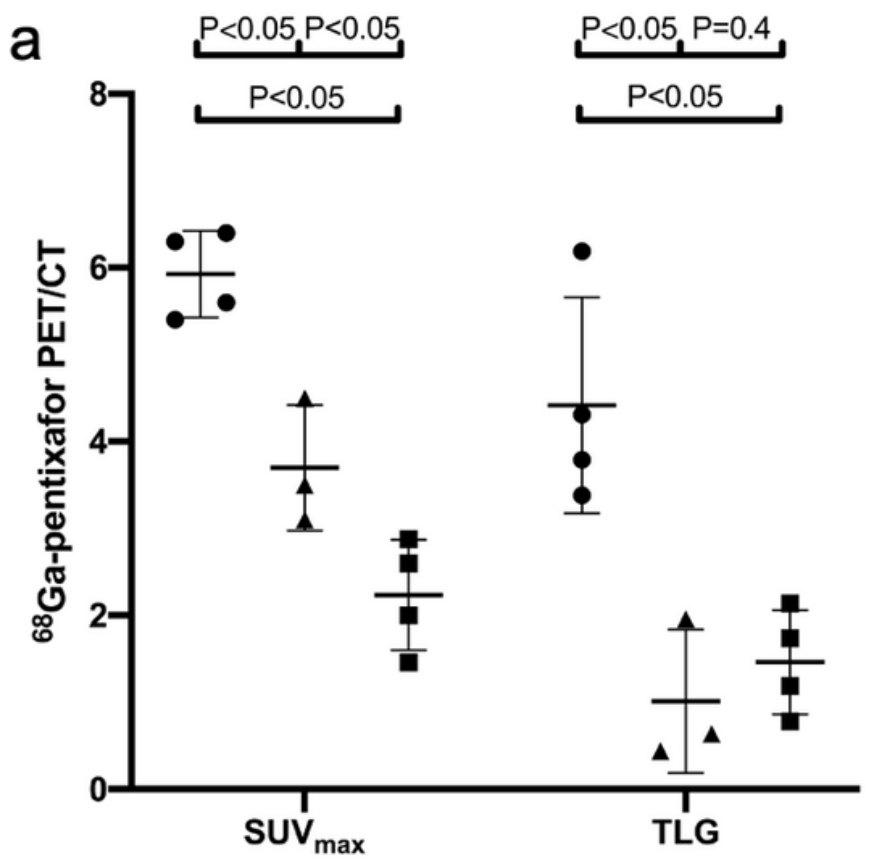

- Primary ACTH-producing pituitary adenoma

- Recurrent $\mathrm{ACTH}$-producing pituitary adenoma

- Non-functional pituitary adenoma

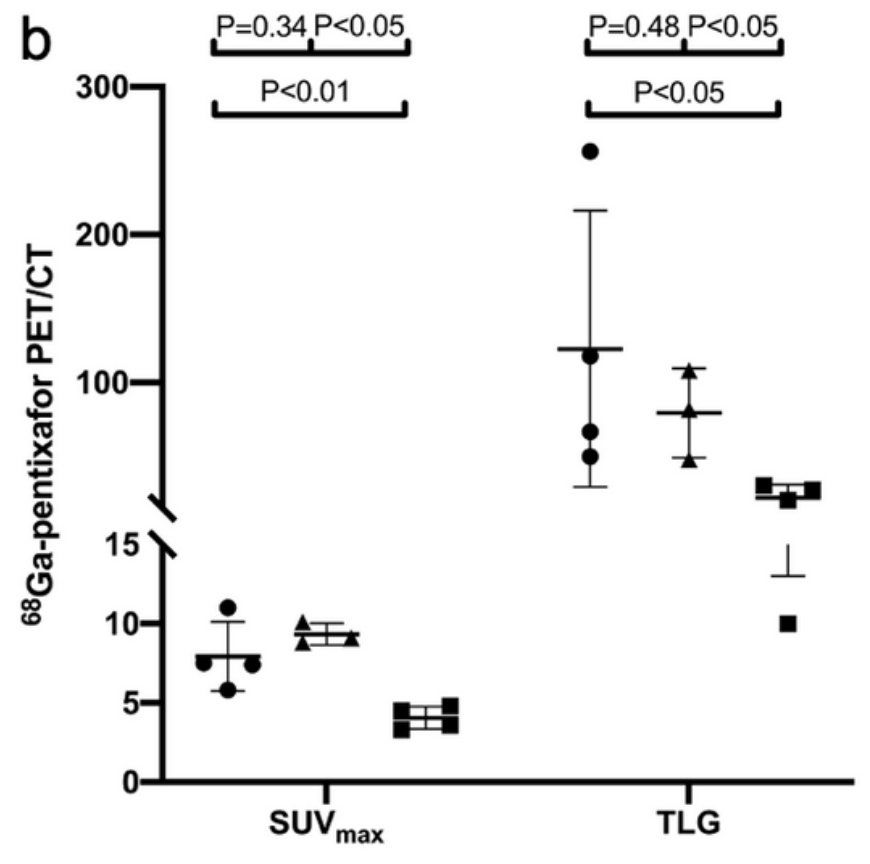

- Adrenal glands in primary CD patients

- Adrenal glands in recurrent $C D$ patients

- Adrenal glands in non-functional pituitary adenoma patients

\section{Figure 3}

a. The comparison of $68 \mathrm{Ga}$-pentixafor SUVmax and TLG between primary ACTH-PAs, recurrent ACTH-PAs and NFPAs. b. The comparison of 68Ga-pentixafor SUVmax and TLG between adrenal glands in primary $C D$, recurrent $C D$ and NFPA patients. 

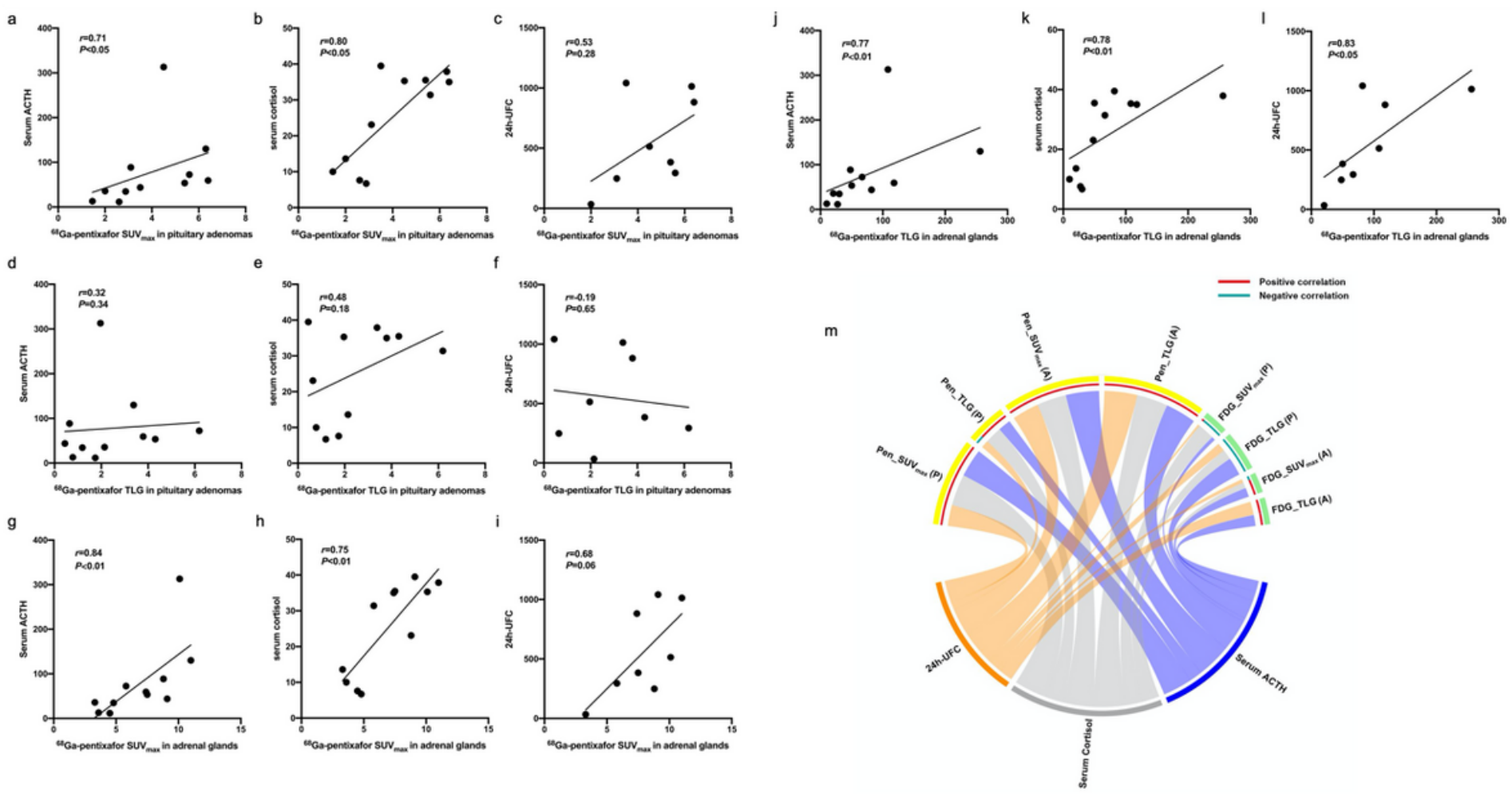

Figure 4

a-f. The correlations of hormone level (serum ACTH, serum cortisol and 24h-UFC) with the uptake of 68Ga-pentixafor in pituitary adenomas (SUVmax and TLG). g-l. The correlations of hormone level with the uptake of $68 \mathrm{Ga}$-pentixafor in adrenal glands. $\mathrm{m}$. The correlation networks showed the pituitary-adrenal axis hormone level was more associated with the uptake of 68Ga-pentixafor in pituitary adenomas and adrenal glands than 18F-FDG.

\section{Supplementary Files}

This is a list of supplementary files associated with this preprint. Click to download.

- supplement.docx 